\title{
COGNIÇÃO E APRENDIZAGEM NO ESPAÇO DA TECNOLOGIA
}

\author{
COGNICIÓN Y APRENDIZAJE EN EL ESPACIO DE LA TECNOLOGÍA
}

\author{
COGNITION AND LEARNING IN SPACE TECHNOLOGY
}

Kelber Ruhena ABRÃO ${ }^{1}$

José Cláudio DEL PINO ${ }^{2}$

RESUMO: Este trabalho analisa o impacto das Novas Tecnologias nas situações didáticas cotidianas. Trata-se de uma pesquisa qualitativa, um Estudo de Caso descritivo, baseado em observações dos espaços das salas de aula, do mesmo grupo de crianças, entre junho de 2013 e abril de 2015, nos $1^{\circ}, 2^{\circ}$ e $3^{\circ}$ anos do Ensino Fundamental de uma escola particular católica, bem como entrevistas com as professoras regentes destas turmas. Buscamos estabelecer relações entre a aquisição da linguagem escrita em textos convencionais e aqueles em hipertextos, assim como compreender como se estrutura a alfabetização científica e digital nesses espaços. Nesse sentindo, verificou-se que essas experiências são possíveis de acontecer em espaços projetados de forma antagônica aos espaços tradicionais, pois, muitas vezes, a mesma é menos rígida, mais flexível, fato este que torna o ambiente agradável e, ao mesmo tempo, mais acessível, constituindo um ambiente, por vezes, híbrido, no qual as dimensões entre o caderno e o tablet coexistem e a fusão desses pares opostos de aquisição de linguagem escrita acontece.

PALAVRAS-CHAVE: Cognição. Linguagem Escrita. Tablet.

RESUMEN: Este trabajo analiza el impacto de las Nuevas Tecnologías en las situaciones didácticas cotidianas. Se trata de una investigación cualitativa, un Estudio de Caso descriptivo, basado en observaciones de los espacios de las salas de clase, del mismo grupo de niños, entre junio de 2013 y abril de 2015, en los $1^{o}, 2^{\circ}$ y $3^{\circ}$ años de la Enseñanza Básica de una escuela particular católica, así como entrevistas con las profesoras responsables por estos grupos. Buscamos establecer relaciones entre la adquisición del lenguaje escrito en textos convencionales y aquellos en hipertextos, así como comprender como se estructura la alfabetización científica y digital en estos espacios. En ese sentido, se observó que esas experiencias son posibles de ocurrir en espacios proyectados de forma antagónica a los espacios tradicionales, pues, muchas veces, la misma es menos rígidas, más flexible, hecho éste que torna el ambiente agradable y, al mismo tiempo, más accesible, constituyendo un ambiente, por veces, híbrido, en el cual las dimensiones entre el cuaderno y el Tablet coexisten y la fusión de estos pares opuestos de adquisición del lenguaje escrito ocurren.

PALABRAS CLAVE: Cognición. Lenguaje Escritura. Tablet.

\footnotetext{
${ }^{1}$ Professor Adjunto da Universidade Federal do Tocantins (UFT). Bolsista Produtividade em Pesquisa pela UFT e Professor Permanente do Programa de Pós Graduação em Ensino de Ciências e Saúde (PPGECS). E-mail: kelberabrao@gmail.com

${ }^{2}$ Professor-Orientador do PPG Educação em Ciência Química da Vida e Saúde e do PPG Química ambos da Universidade Federal do Rio Grande do Sul. Bolsa de Produtividade em Pesquisa do Conselho Nacional de Desenvolvimento Científico e Tecnológico. E-mail: delpino.jc@yahoo.com.br
} 
ABSTRACT: This work analyzes the impact of new technologies in everyday teaching situations. This is a qualitative research, one study of descriptive case, based on observations of the spaces of the classrooms, the same group of children between June 2013 and April 2015, the 1st, 2nd and 3rd years of Primary Education a Catholic private school, as well as interviews with the regents' teachers of these classes. We seek to establish links between the acquisition of written language in conventional texts and those in hypertext, as well as understand how to structure the scientific and digital literacy in these areas. In that sense, it was found that these experiences are possible to happen in designed spaces antagonistically to traditional spaces as often, it is less rigid, more flexible, a fact that makes the pleasant atmosphere and at the same time, more accessible, providing an environment sometimes hybrid, in which the dimensions of notebook and tablet coexist and fusion of these opposed pairs of written language acquisition occurs.

KEYWORDS: Cognition. Written language. Tablet.

\section{Introdução}

A descoberta da Imprensa, no século XV, permitiu a disseminação do conhecimento às mais diversas esferas da população, ao passo que, para os estudiosos, houve um aumento considerável de acesso aos acervos de obras culturais e científicas. Com as evoluções socioculturais e tecnológicas ao longo da história, ocorreram incessantes mudanças na forma de organizar o pensamento e o planejamento humano, haja vista que o estímulo atrativo das Novas Tecnologias concorre, diariamente, com a rotina da maioria das escolas. O resultado de tal disputa é uma sala de aula cada vez menos atraente, com alunos cada vez mais desinteressados no que ela propõe.

Atualmente, e considerando tal revolução com o uso das Tecnologias da Informação, tanto o giz quanto o quadro-negro já não são mais suficientes para o exercício da docência, como também o abuso de recursos didáticos como retroprojetor e vídeos acabam desestimulando os alunos. Apesar de todas essas iniciativas e da ampliação dos sistemas de telecomunicações ter permitido um grande avanço nas interações entre os sujeitos nas últimas duas décadas, no meio educacional ainda estamos habituados a pensar mais em um resultado referente ao mercado de trabalho do que mesmo na questão de conhecimentos e aprendizagens que poderão advir do uso dessas tecnologias (ALMEIDA, 2012). O autor, evidencia preocupações quanto à educação das pessoas, como o acesso, a qualidade e o custo, pois, de certa forma, o ensino institucionalizado não atinge milhões de brasileiros uma vez que, de acordo com a mais recente Pesquisa Nacional por Amostra de Domicílios (Pnad), realizada pelo Instituto Brasileiro de Geografia e Estatística (IBGE) em 2012 e divulgada em setembro de 2013, a 
taxa de analfabetismo de pessoas de 15 anos ou mais foi estimada em 8,7\%, o que corresponde a 13,2 milhões de analfabetos no país.

Assim como a alfabetização é classificada em níveis diferenciados, considerando o analfabetismo, o analfabetismo funcional e o alfabetizado, a área das novas tecnologias igualmente nivela a alfabetização tecnológica ou digital provocando a exclusão educacional de milhares de sujeitos em todo o país, pois tanto as condições geográficas quanto as sociais, econômicas e culturais presentes em nosso sistema educacional permitem-nos concordar com estudos como de Lankshear e Knobel (2008). Tais estudos relatam que o uso da tecnologia educacional está voltado para as necessidades dos professores e não, infelizmente, para a dos alunos, uma vez que a sala de aula não utiliza os mesmos recursos digitais que os estudantes, aqueles que permitem a esses sujeitos estarem imersos nos ambientes extraclasses, como, por exemplo, os computadores pessoais e tablets. É cada vez mais comum alguns cursos de especialização darem de presente aos cursistas tablets para que os mesmos os utilizem durante o curso -, pensamos ser comum, igualmente, o uso deste recurso como parte do cotidiano em escolas brasileiras, em especial as particulares. Porém, ainda não existe um consenso estabelecido para seu uso de forma efetiva, aliado à aprendizagem. As interfaces tangíveis para a educação podem ser definidas como recursos didáticos inovadores nos quais a computação é embutida em objetos concretos, unindo as vantagens da manipulação física às formas de interação providas pela tecnologia (KULIK, 2003).

De acordo com o exposto, este artigo surge a partir da necessidade emergente de estudos como Brasil (2012) cujo foco é a necessidade de que todas as crianças brasileiras estejam alfabetizadas ao término de seus oito anos de idade. A elevação da qualidade da Educação Básica brasileira demanda investimentos com vistas à ampliação da qualidade dos processos de alfabetização, no ensino e aprendizagem da Língua Portuguesa e da Matemática, das crianças e jovens que cursam o Ensino Fundamental. Esse fato justifica o Pacto Nacional pela Alfabetização na Idade Certa (PNAIC), tendo por base análises dos dados do Instituto Nacional Ensino e Pesquisas (INEP), sobre as escolas municipais da cidade de Pelotas/RS e o Índice de Desenvolvimento da Educação Básica (IDEB) do ano de 2013, no qual se verificou um decréscimo de $2 \%$ na qualidade de ensino, com uma média de 3.9 nos anos iniciais do Ensino Fundamental, enquanto a média estadual ficou em 4.9. Já a média para as escolas particulares ultrapassou o esperado, ficando em 6.7. A rede pública encontra-se muito aquém da rede particular de 
ensino e, dentro da própria estrutura estatal, há enormes variações de desempenho. Nota-se que há uma considerável diferença entre as esferas administrativas públicas. A rede municipal apresenta desempenho inferior às escolas particulares, perdurando essa disparidade em todos os levantamentos realizados até hoje.

A partir disso, tendo por base os altos índices das escolas particulares, apresentamos o problema de pesquisa deste manuscrito: Como acontecem os processos de construção da linguagem escrita em crianças por meio do uso de tecnologias tangíveis? Tal questionamento visa entender a proposta, tecnologicamente ousada, de uma escola particular do município de Pelotas/RS, no qual todo o material, tanto do professor quanto dos alunos, pode ser acessado por $i P a d s^{3}$ de última geração. $\mathrm{O}$ principal objetivo que sobrevém desse problema é analisar o impacto das Novas Tecnologias nas situações didáticas cotidianas.

\section{Linguagem e Pensamento}

Nos diversos períodos históricos, em especial do Neolítico até a Antiguidade, a linguagem de gestos era suposta como a forma mais primitiva de comunicação, dividindo, o espaço com a linguagem oral. $\mathrm{O}$ fato de liberar as mãos e permitir a continuidade da atividade que o homem executava naquele momento, possibilitou, assim, uma melhor comunicação.

Os desenhos das cavernas, objetos de barro e fragmentos de civilizações são alguns dos sinais da presença humana que preservam a cultura de diversos povos, dos quais alguns já não existem mais. Porém, foi a linguagem verbal que possibilitou, sem dúvida, a transmissão desse patrimônio cultural a outras gerações (LÉVY, 1996).

A linguagem oral era utilizada pelos antigos como elemento de gestão da memória social, pois toda experiência, assim como descobertas e acervo cultural desses povos e civilizações se encontravam armazenados somente na memória dos indivíduos. Esse tipo de oralidade é entendido por Lévy (1999) como primária; já a oralidade que utilizamos hoje e que coexiste juntamente com a linguagem escrita é denominada pelo autor como secundária. Dessa forma, a memória humana, com suas redes de associações e representações, ainda está longe da precisão do armazenamento e da recuperação de informações que caracteriza os computadores, por exemplo.

\footnotetext{
3 Nome comercial dado ao tablet que está sendo usado pela Uno Internacional nesta proposta de alfabetização. da marca Apple, cujo controle é, exclusivamente, tangível.
} 
Nos ambientes escolares das sociedades sem a escrita, as proposições eram impostas aos indivíduos de forma repetida e retomadas em voz alta, sendo esta a principal forma de armazenar o conhecimento, caso contrário, o mesmo estaria fadado a desaparecer. Dessa forma, o processo de audição e repetição era tido como a melhor forma de aprendizagem. Enquanto a palavra oral era ajustada às necessidades e circunstâncias do momento, na época a escrita separou os discursos, criando longas perspectivas na história, acumulando saberes, libertando a memória humana do papel de guardiã da informação (LÉVY, 1996).

A relação entre cognição e aprendizagem pode ser explicada como consequência do dualismo ontológico e, sendo assim, o fenômeno mental (cognitivo) é primeiramente vinculado ao biológico e concebido praticamente à margem da linguagem (MORATO, 2000). Para tanto, o conhecimento não procede nem da experiência única dos objetos, tampouco de uma ampla programação pré-formada do sujeito, mas sim de construções sucessivas com elaborações constantes de novas estruturas. Nesse sentindo, verifica-se uma relação entre sujeito e objeto, onde um dos termos não se opõe ao outro, mas se solidarizam, formando um todo (GIUSTA, 1985).

De acordo com esse pensamento, a cognição humana é uma forma de adaptação biológica na qual o conhecimento é construído aos poucos e a partir do desenvolvimento de estruturas cognitivas que se organizam de acordo com os estágios de desenvolvimento da inteligência (PIAGET, 1976). Ainda em relação à cognição, vale destacar que após o surgimento do computador, bem como da modelagem computacional, ocorreu um aumento significativo nos estudos sobre a cognição humana atrelada a sua relação com a área computacional. A ciência cognitiva, desse modo, é uma área de estudos interdisciplinares que, de certa forma, se inter-relacionam.

Considerando a era da informática, o cérebro humano pode ser comparado com uma máquina processadora à semelhança do computador, tanto que Borges et al. (2004, p.79) relatam que ele, o cérebro humano, apresenta dispositivo de entrada (sistema sensor), saída (sistema efetor), unidades de processamento (certas partes funcionais do cérebro). Considerado como um "processador de informação", o cérebro humano é tido como o melhor já existente, uma vez que o ato de conhecer se resume a um algoritmo de captar, representar, armazenar, recuperar e processar os atributos, coisas ou regras para transformar símbolos.

Para tanto, o desenvolvimento cognitivo está ligado aos processos de assimilação e acomodação e esses variam de acordo com a idade do sujeito. Piaget 
(1975) define o primeiro como o processo cognitivo através do qual uma pessoa integra um novo dado às estruturas cognitivas prévias, de forma prática. É quando uma criança apresenta um esquema sobre o que é um cachorro e a mesma visualiza um cavalo, que, de certa forma, apresenta algumas características semelhantes e, então, define o cavalo como sendo um cachorro. A mediação de um adulto faz-se necessária neste processo para que ensine a criança e indique como se denomina o animal, apontando diferenças além das semelhanças. Já o outro processo, a acomodação, é toda modificação dos esquemas de assimilação sob a influência do meio externo. Com isso, podemos compreender que, em relação à aprendizagem, existem dois polos importantes: um deles é o sujeito, que assimila o mundo e o transforma, e o outro é o próprio mundo que, ao ser assimilado pelo sujeito, modifica-se e com ele interage, pois quando o sujeito age sobre um objeto, este, no mínimo, oferece uma resistência a tal ação. Esta ação, por vezes, é mais explicita, sendo a ação propriamente dita que o objeto exerce sobre o sujeito. Portanto, toda ação é, de fato, uma interação. É uma ação que se dá entre dois polos (o sujeito e o objeto). Deste modo, o conhecimento é fruto de uma ação concomitante do sujeito que conhece e do objeto que é conhecido (PIAGET, 1976).

É com essa intencionalidade pedagógica que surge uma nova sala de aula, voltada à alfabetização exclusivamente permeada pelas Novas Tecnologias e apresentada à escolas privadas da América Latina, sendo adotada em países como Argentina, Colômbia, Equador, e a partir de 2013, no Brasil. Esse projeto é coordenado pela Uno Internacional, uma das maiores produtoras de material didático do mundo que, no Brasil, controla a Editora Moderna. A proposta é incorporar a internet no dia a dia da escola. Conteúdos, tarefas e todo o material didático estariam disponíveis não apenas nos iPads da escola, mas, também, em qualquer computador ou dispositivo móvel.

Nesse sentido, o modelo tradicional de ensino, no qual as aulas envolvendo tecnologias usavam como espaço o laboratório de informática deixa de existir, pois antes havia um horário pré-estabelecido para o uso, sendo que, no restante do tempo, o aluno ficava desconectado. No Ambiente virtual, ele passa a ser estimulado e a utilizar as Novas Tecnologias a todo momento. A proposta é que as escolas adquiram as licenças de uso dos equipamentos e atualizações da Apple $e^{4}$ que serão sempre renovados à medida que lançarem novos modelos de equipamentos no mercado.

\footnotetext{
${ }^{4}$ Empresa norte-americana que comercializa, principalmente, softwares e computadores pessoais.
} 
Desta forma, o ciberespaço cria um novo meio de comunicação com o advento das Novas Tecnologias, ou seja, microprocessadores, usados nos computadores pessoais, abrindo espaço para a interatividade da realidade aumentada, da simultaneidade e da interação entre o local e o internacional. Para avaliar essas novas formas de conhecimento, é preciso pensar sobre as tecnologias como uma ecologia cognitiva em vias de formação, pois a verdadeira mutação introduzida pela linguagem digital é o fato de o leitor não mais deslocar-se diante do texto, mas de o texto, então, deslocar-se de forma diferente para cada leitor (LÉVY, 1999).

Sendo assim, a partir dessa proposta atual da Rede Uno Internacional, temos uma nova configuração de alfabetização. Se anteriormente, para operar um computador a criança, minimamente, deveria conhecer algumas letras para poder manipulá-lo, isto é, pelo menos reconhecê-las no teclado, com o advento das Tecnologias Tangíveis o processo de alfabetização deixará de ser um processo mecânico de cópia de letras e palavras. Irá, pois, possuir um sentido, um significado para o alfabetizando, uma vez que o processo de alfabetização deve partir do contexto dele, de seu "universo existencial" que é seu mundo. Pensando nesse indivíduo que interage com o meio tecnológico desde a mais tenra infância, ou seja, com as Novas Tecnologias - pois se diz que se deve ler o mundo antes -, podemos perceber que essa leitura inicia-se bem mais cedo do que se imagina, antes mesmo de as crianças entrarem na escola, uma vez que já estão imersas no mundo dos celulares, computadores, televisão, internet e tantas outras tecnologias existentes.

\section{Procedimentos Metodológicos}

A metodologia empregada foi o Estudo de Caso. Optamos por esse tipo de pesquisa porque permite uma maior profundidade sobre o tema a ser abordado e, ainda, possibilitar o uso de múltiplas fontes de evidências (YIN, 2010). Além disso, o uso do estudo de caso com a finalidade de pesquisa permanece como um dos empreendimentos mais desafiadores das ciências sociais no qual "a essência de um estudo de caso, a tendência central entre todos os tipos de estudo de caso, é que ele tenta iluminar uma decisão ou um conjunto de decisões: por que elas são tomadas, como elas são implementadas e com que resultado" (SCHRAMM, 1971, p. 78). Desta forma, decisões, para o autor, são investigações empíricas que investigam um fenômeno contemporâneo 
em profundidade e em seu contexto de vida real, quando os limites entre os fenômenos e o contexto não são claramente evidentes (ibidem).

Inicialmente, começamos por uma revisão minuciosa da literatura, levando em conta a proposição cuidadosa e atenta em consonância com os objetivos propostos pela pesquisa, a qual apresenta o seguinte problema: Como acontecem os processos de construção da linguagem escrita em crianças por meio do uso de tecnologias tangíveis? Trata-se de uma análise contemporânea de relações que acontecerão, normalmente, durante a coleta de dados, o que é uma característica típica desse tipo de metodologia.

A unidade de caso constitui-se da primeira turma a ser aplicado o uso de Tecnologias Tangíveis para o processo de alfabetização, acompanhada durante o $1^{\circ}, 2^{\circ} \mathrm{e}$ $3^{\circ}$ anos do Ensino Fundamental de uma escola particular do município de Pelotas/RS, nos anos de 2013, 2014 e 2015. Para não alterar a rotina da turma observada, realizamos uma observação de um turno (das 13h30min às 17h30min) uma vez por mês, perfazendo um total de 56 horas e entrevistas do tipo semiestruturada as professoras regentes.

A capacidade de acessar o conhecimento a qualquer momento e lugar, amplia as possibilidades de ensino e da aprendizagem. Nesse sentindo, ela - aprendizagem móvel - pode ser usada em sala de aula para resolver uma tarefa de ciências, por exemplo, em conjunto com seus pares assim como o professor também pode usá-la fora da sala de aula como uma saída de campo. Tal facilidade oferece a possibilidade do estudante experienciar, em contexto mais próximo, contextos de realidade, gerando-lhes mais autonomia e responsabilidade em seu processo de aprendizagem (WARSCHAUER e AMES, 2010).

\section{A construção da escrita em língua materna e estrangeira}

Quando tratamos da língua materna, nosso próprio organismo constrói uma série de conhecimentos através de estímulos do meio, ou seja, é a língua falada por todos e entendida por todos que está presente na maioria dos nossos momentos e em nossas vidas, seja na fase infantil ou adulta. Isso é o que Piaget (1976) denomina de assimilação, isto é, o processo no qual se desestabiliza um conjunto de informações préexistentes, em que o sujeito recebe a informação que passa a ser internalizada, compreendida e utilizada quando há esta internalização. Este é entendido como o 
processo de acomodação, ou seja, o tempo individual que esta informação necessita para ser utilizada novamente, de forma que todo o conhecimento perpasse por esse processo cíclico.

Nesse sentido, podemos, então, discutir os fatores extrínsecos da aprendizagem de uma segunda língua, que, de certa forma, resume-se a estimulação externa. Tal fato advém da figura do professor em gerar em seu aluno a curiosidade, motivação, interesse e desejo de aprender para que este sujeito consiga perceber a funcionalidade do conteúdo desenvolvido.

Para que isso seja possível, o professor necessita se valer, pedagogicamente, de diversas metodologias, estando atento as necessidades dos alunos e utilizar diferentes situações de aprendizagem, pois a resposta do aluno frente ao desinteresse é imediata (Diário de Campo, professora 1, ano 2013).

Dessa forma, tanto o estímulo ofertado pelo professor quanto a motivação do aluno serão os eixos norteadores do trabalho pedagógico, uma vez que ambas as partes são importantes para o processo de ensino e aprendizagem, seja da língua materna quanto da estrangeira. Assim, deve-se levar em conta a ludicidade dos jogos, brincadeiras, músicas, sempre respeitando a especificidade de cada criança, observando os conhecimentos prévios de cada um com a língua estrangeira para que a ela perceba a funcionalidade da língua.

É muito difícil trabalhar só com a língua materna, com o inglês dificulta um pouco, mas não tanto quanto o espanhol porque grande parte dos alunos tem smartphones mesmo tão pequenos, então já estão imersos a uma cultura inglesa, assim como os jogos de vídeo game, redes sociais, o espanhol não trabalhamos tanto, até mesmo porque em 2013 não havíamos aderido ao PE, então fizemos o cantinho do espanhol na sala, onde lá temos alguns cartazes. Ensinamos também as expressões do cotiado (Diário de Campo, professora 2, ano 2014).

Quando se trabalha com a aquisição de uma língua estrangeira, seja ela inglesa ou a espanhola, sem estarmos aqui analisando o processo de bilinguismo, deparamo-nos com um complexo panorama de problemas que ainda não puderam ser solucionados quando nos referimos à aquisição de uma segunda língua, no qual, destacamos o tempo necessário da apreensão dos elementos em uma segunda língua e a relação destes com o concreto.

Para tanto, em língua materna, relacionamos cada palavra com um objeto concreto existente, ou muito conhecido pela memória auditiva do falante, aqui no caso a criança. No entanto, quando referimo-nos a uma segunda língua, acabamos por 
estabelecer ligações de tradução, impossibilitando que a criança organize mentalmente a linguagem e favoreça, assim, somente a estrutura fonética entre os elementos das duas línguas. Isso dificulta, por vezes, a compreensão geral da língua, fazendo com que a criança realmente se expresse e se encontre na fala desse segundo idioma (BUENO e LEAL, 2003).

Partindo da ideia de interação enquanto processo que leva ao desenvolvimento da linguagem, Chomsky (1998), tendo por base uma perspectiva interacionista, definiu que a linguagem corresponde a uma das habilidades especiais e inerentes aos seres humanos, a qual pode ser compreendida como um sistema de sinais de duas faces, elencados como significante e significado. Para este autor, o significante refere-se ao aspecto formal da linguagem, constituído pela junção de elementos como fonemas, palavras, orações e discursos, no qual os fonemas integram as palavras, as palavras formam orações que, por sua vez, se enquadram nos discursos. O significado, por sua vez, refere-se ao aspecto funcional da linguagem, sendo considerado o responsável pela comunicação no meio social. Nesse sentindo, o conceito de significado e significante foi introduzido nos estudos sobre a aquisição da linguagem devido à necessidade de se considerar o papel semântico da fala, visto que apenas a sintaxe não daria conta de explicar as produções linguísticas que são sintaticamente corretas, mas que não são empregadas na fala (ABRÃO et al., 2014).

Piaget, na década de 20, fazia as primeiras aproximações entre as conquistas conceituais realizadas pelas crianças e como estas são explicadas em detrimento da socialização linguística e das interações sociais. Segundo este autor, a socialização da criança pode ocorrer de forma implícita por meio da participação em interações verbais que têm marcações sutis de papéis e status. A linguagem é tida como a primeira forma de socialização da criança, sendo na maioria das vezes efetuada de forma explicita pelos pais das crianças através de instruções verbais (ELY e GLEASON, 1996).

A fim de tentar resolver os problemas epistemológicos, Piaget realizou pesquisas psicogenéticas sobre as origens e a estruturação progressiva do conhecimento, investigando o papel da lógica e da linguagem. Em sua obra Linguagem e pensamento da criança em 1923, expõe o resultado de suas pesquisas sobre o comportamento linguístico e o pensamento lógico das crianças, atribuindo a interação social como papel fundamental no desenvolvimento do pensamento e da linguagem infantil.

Com base nos estudos de Piaget sobre a linguagem, Austin $(1976,1990)$ a partir da década de 70, incorporou a visão pragmática, a qual da ênfase aos fatores 
comunicativos da linguagem, devido à necessidade de relacioná-la com o contexto da fala. Para Austin (1990), a linguagem deve ser analisada no momento da fala, dentro do contexto social e cultural na qual é utilizada, analisando a intenção do uso de acordo com algumas normas e convenções da língua.

Desta forma, a visão pragmática considera que a linguagem é desenvolvida a partir da interação entre os processos biológicos e sociais, na qual a interação social é um componente necessário, devido à linguagem só se desenvolver mediante o seu próprio uso. Sendo assim, considera-se, nessa perspectiva, que é a partir das práticas comunicativas estabelecidas nas interações cotidianas entre as crianças e seus parceiros de nível linguístico mais avançado, que estes últimos proporcionam às crianças os recursos necessários para a facilitação do seu desenvolvimento linguístico (AUSTIN, 1976).

Ainda para o autor, a psicolinguística questiona a reação entre o aprendizado visual, ocorrido na língua materna, e o auditivo, que geralmente ocorre na aquisição da segunda língua, assim como até que ponto essa diferença poderá dificultar o processo de aprendizagem, de forma que a criança-aluno acabe por apresentar dificuldades entre estabelecer significante e significado (PIAGET, 1976), questionando, assim, a funcionalidade da segunda língua que está aprendendo, conforme podemos observar na conversa a seguir:

- Tia quem fala inglês?

- Os Ingleses, por exemplo.

- Ah, hum...

- E espanhol?

- Os espanhóis, por exemplo.

- E se nós, não somos nem ingleses e nem espanhóis porque estamos aprendendo isso $i$

- Porque é importante que todos nos conheçamos outras culturas, outros países e, também outros idiomas?

- Hum... nós devíamos aprender brasileires, isso sim

(Diário de Campo, professora 1 aluno B, ano 2013).

O desenvolvimento cognitivo da criança, no período dos 4-6 anos, necessita de um método concreto em que a mesma viabilize o processo de assimilação e acomodação da informação, uma vez que a construção da linguagem em outra língua que não a materna, torna-se abstrata por não relacionar-se com o significado e sim com o significante da mesma (PIAGET, 1976). De forma mais clara, percebemos que a criança não possui a noção da existência dos diversos idiomas espalhados pelo mundo, já que, para ela, quando é dado outro nome para algo que ela já havia nomeado, seria como se 
estivéssemos negando o seu conhecimento prévio e refutando o antigo nome do objeto (ibidem).

Para que a criança entenda que em cada lugar há um idioma, uma língua, um dialeto diferente, requer da mesma uma boa noção de tempo e espaço, uma vez que para a mesma é muito difícil compreender a dimensão de espaço para além do ambiente físico que a mesma se relaciona, como, por exemplo, casa, escola, família (ABRÃO, 2014).

Nesse sentido, a linguagem, apenas, não é suficiente para explicar o pensamento, pois as estruturas que caracterizam o pensamento têm origem na ação e nos mecanismos sensório motores, sendo mais profundos do que o fato linguístico, e, quanto mais refinadas as estruturas do pensamento, mais a linguagem se faz necessária para complementar a elaboração delas, pois entre esta e o pensamento, existe a inteligência que é anterior a linguagem e independente dela (PIAGET,1967).

Se tomarmos por base a língua como uma habilidade, como hábitos automáticos referentes à comunicação humana, veremos a língua materna como um processo de reprodução mecânica, diferentemente da língua estrangeira, na qual o sujeito passa por um processo de construção e desconstrução de alguns conceitos referentes à língua materna. Por se tratar de um processo demorado, que necessita de um rigor sistemático e sequencial, devemos considerar a etapa do desenvolvimento cognitivo que o sujeito está para que esta construção seja funcional e para que a criança sinta-se à vontade com estas novas expressões. Isso porque se sabe que, conforme estudos de Titone (1983) e Carrol (1960), mesmo que ficasse provado que as crianças aprendem as línguas de forma mais rápida, ainda teria que se levar em conta o fato que muitas encontram uma grande dificuldade. Tal situação é nomeada pelos autores supracitados de aptidão linguística.

Com base nisso, pode-se traçar um paralelo com a teoria chomskyana (1998), a qual menciona que cada indivíduo nasce com uma carga inata de estruturas linguísticas que são biologicamente programadas, ou seja, de forma fonética, morfológica e, até mesmo, sintática, o que muitos chamam de gramática internalizada. No entanto, para o autor, possuímos a gramática internalizada de todas as línguas do mundo, mas ativamos o que nos é conveniente, e, no caso da infância, apenas a língua materna. A partir disso, este seria o motivo pelo qual crianças tenderiam a ter maior aptidão linguística que adultos, ou seja, a criança menor de 11 anos de idade possui os esquemas cerebrais com maior flexibilidade, o que a predispõe à aquisição de conhecimentos (CHOMSKY, 1998). 
Desse modo, ao aprender uma língua estrangeira, a criança acaba por sentir prazer nesta e passa a buscar uma funcionalidade dos conteúdos desenvolvidos pelo professor. Além disso, essa criança possui, no seu tablet, uma biblioteca digital que engloba desde os livros didáticos usados em sala de aula até aplicativos voltados ao ensino de língua inglesa e espanhola para crianças.

Nesse cenário, as cartilhas foram taxadas de não confiáveis, mesmo as mais tradicionais como a Caminho Suave ${ }^{5}$. Alfabetizar-Letrar uma criança, indo letra por letra do A a Z, não satisfaz mais as teorias vanguardas dessa área de estudo. Já não se aconselha mais o uso de palavras simples, como, bolo, bala, ou até mesmo frases sem sentido, tais como a baba do boi é boa, para o trabalho da letra "B". No entanto, é preciso conhecer a historicidade das práticas de alfabetização para poder, então, transitar em novas abordagens pedagógicas. Para os padrões de editoração de materiais pedagógicas da época, a mesma era considerada inovadora, pois alfabetizava a partir da imagem para capturar o interesse da criança, tanto na leitura quanto na escrita. A abordagem proposta pelas tecnologias tangíveis também tem esse viés.

No modelo de cartilhas, a escrita era feita de forma cursiva, porém com as tecnologias tangíveis o modo pelo qual as crianças se apropriam da escrita é de forma, pois ao invés de escrever, as mesmas digitam as palavras no teclado virtual. Porém, há aplicativos no tablets que permitem que a criança aprenda a forma cursiva.

Temos nos ipads diversos app os quais nossas crianças podem fazer o mesmo movimento de escrita que usam ao usar o convencional lápis. No entanto, a proposta da escola é se preocupar com o investimento maior em tecnologias de escrita digitais, as quais serão mais comuns nas próximas décadas. Sei que para diversos professores, pais e até mesmo alunos, isso é impensável, porém usar a letra cursiva demanda um tempo de apropriação do código escrito muito maior d que o digital. Não me resta dúvida de que nossos alunos precisam aprender a escrever à mão, porém o que preciso aqui questionar é se a forma cursiva ainda continua a ser adequada, até mesmo porque as escolas, especialmente as públicas, não dão conta de ensiná-las, demandando diversos programas para repensar as formas de alfabetizar as crianças. Se você for ver, onde além da escola escrevemos de forma cursiva? (Diário de Campo, professora 2, ano 2014).

Tendo por base o excerto da professora 2, podemos observar que o avanço das novas tecnologias nem sempre correspondeu à aniquilação das antigas técnicas. As novas tecnologias das escritas digitais, hoje, principalmente, no sistema privado de

${ }^{5}$ Cartilha de alfabetização. Desde sua primeira edição, em 1948, até meados da década de 1990, foram vendidos 40 milhões de exemplares. Em 1995, a obra foi retirada do catálogo do Ministério da Educação. Apesar de não ser mais o método "oficial" de alfabetização das crianças brasileiras, a cartilha Caminho Suave ainda vende cerca de 10 mil exemplares por ano. 
ensino, estão promovendo novas e mais flexíveis formas de lidar com a escrita e, sem dúvida, as escolas não podem ficar alheias a estas tecnologias digitais, uma vez que, assim como relata a professora entrevistada, a escassa letra cursiva quase não circula mais nos espaços da sociedade e, constantemente, questiona-se sobre sua utilidade nestes. No ambiente digital, ela marca presença em letras capitulares de livros ou usadas em marcadores de leitura, principalmente os infantis, tais como Era uma vez e Fim.

Nesse sentindo, a linguagem pode ser definida como um sistema de signos que serve tanto para expressar ideias quanto sentimentos, possuindo um caráter formal e funcional. No que tange ao aspecto formal, desenvolver a linguagem é aprender a produzir e ao mesmo tempo usar os signos, sejam eles alfabéticos, lexicais, sintáticos ou discursivos (ABRÃO et al., 2014). Isto pode ser corroborado pela fala da professora abaixo:

A produção de um texto escrito necessita, por parte dos alunos, toda uma série de elementos para que estruturação do discurso saia da mente ou fala para o papel, como, por exemplo, a coesão, a argumentação, a organização de ideias a escolhas das palavras, o objetivo da escrita daquela frase, daquele texto e até mesmo o destinatário (Diário de Campo, professora 3, março de 2015).

Ao pensamento dessa professora, Brasil (1997) cita que a prática de produção de textos tem como finalidade

formar escritores competentes capazes de produzir textos coerentes, coesos e eficazes, e também aborda alguns procedimentos didáticos para programar uma prática continuada de produção de textos na escola, como: a conversa entre professor e alunos é [...] uma importante estratégia didática em se tratando da prática de produção de textos: [...] assim, é fundamental que os alunos saibam que escrever, ainda que graficamente para muitos, não é fácil para ninguém (p.23).

$\mathrm{Na}$ maior parte do tempo, as crianças possuem as ideias, mas apresentam uma dificuldade na produção textual para organizar suas proposições (coerência), assim como estabelecer um encadeamento através de estruturas inter-relacionadas (coesão). Com o decorrer dos anos escolares, as mesmas passam a aprender, gradativamente, o uso das letras maiúsculas, bem como a pontuação, refletindo o grau de interiorização de suas funções no texto que vai desde leitora até produtora. Quanto a isso, a professora faz o seguinte relato:

Temos uma preocupação muito grande quanto ao uso da pontuação e a escrita de letras maiúsculas. Eles possuem um vício de escrita muito grande que já é, muitas vezes, anterior ao processo de alfabetização. Você quer um exemplo prático? o verbo ser, por exemplo. Quase todos escrevem eh, ao invés de é. Além disso, quase não há 
virgulas na escrita digital, assim como as letras maiúsculas. Nomes, cidades início de frase... Para mim está é a maior dificuldade do uso dos tablets. Algumas vezes ele (tablet) corrige, outras não. Até nos acostumamos com essa correção, as às vezes, ele não faz e aí, assim como as crianças, nós, muitas vezes, temos preguiça de voltar e corrigir o que ficou errado (Diário de Campo, professora 2, setembro de 2014).

Ainda segundo a professora, as atividades de leitura e de compreensão de texto possibilitam ao aluno se constituir como um sujeito-leitor autônomo, de forma que este perceba o texto tanto nos seus aspectos formais quanto conceituais, discutindo os elementos, a organização das ideias, o significado das palavras e das expressões, o sentido da pontuação e das rimas. Essa ideia de representação, para Kato (1998), deve ser trabalhada tão logo as crianças iniciem o processo de apropriação do Sistema de Escrita Alfabética. Para isso, sugere que os professores utilizem as marcas de produtos, rótulos, propagandas, logotipos, placas de trânsito, bandeiras de clubes, entre outros, possibilitando, assim, que a criança já comece a relacionar o símbolo à palavra. Com isso, o aluno terá a oportunidade de conhecer situações variadas de escritas, reconhecendo, então, esta como uma forma de registro e associando que as ideias se transformam em símbolos, de tal forma que, nas produções e reproduções de textos escritos, as crianças serão orientadas a produzirem textos coesos e coerentes, além de eficazes (ibidem).

De acordo com os estudos de Kleiman (1995), há diferentes modalidades de leitura, como, por exemplo, a leitura para obter informações como nos jornais, a leitura recreativa, como nas histórias em quadrinhos, revistas e romances, e a leitura para compreensão e retenção de informações culturais, como nos livros didáticos e científicos. Para tanto, de certa forma, autor e leitor buscam uma interação mútua na qual o primeiro escreve para ser entendido pelo segundo, fato este que vai depender tanto da habilidade do escritor na produção do texto quanto da habilidade do leitor.

Nesse sentido, ler não consiste, apenas, na decodificação de tudo aquilo que o autor escreveu e insinuou no texto escrito, tanto que o autor elucida tal afirmação quando menciona que:

O leitor constrói, e não apenas recebe um significado global para o texto; ele procura pistas formais, antecipa essas pistas, formula e reformula hipóteses, aceita ou rejeita conclusões. Contudo, não há reciprocidade com ação do autor, que busca essencialmente a adesão do leitor, apresentando para isso, da melhor maneira possível, os melhores argumentos, a evidência mais convincente de forma mais clara possível [...]. Isso não quer dizer que sempre haja necessidade de explicação, mas que o implícito possa se inferido, ou por apelo ao texto ou por apelo a outras fontes de conhecimentos (KLEIMAN, 1995, p. 33). 
Tomando por base os estudos sobre aquisição da linguagem, em um dos trabalhos mais importantes da área, Ferreiro e Teberosky (1986) recorrem, em sua obra, às teorias construtivistas baseadas em Piaget, firmando a teoria a respeito da aquisição da escrita. Nela, há três postulados que servem de base ao desenvolvimento da Psicogênese. O primeiro menciona que o sujeito é ativo, busca e seleciona para aprender; o segundo, relata que nenhum conhecimento começa do zero; e, por fim, o terceiro, afirma que todo conhecimento deve ser reconstruído pelo sujeito que aprende, uma vez que não é possível conhecer sem transformar. Nesse sentindo, as transformações produzidas geram, muitas vezes, erros construtivos, pois servem para que se possa entender como o sistema funciona, tanto que, as autoras afirmam que as implicações desses postulados para a aquisição da escrita podem ser sintetizadas, novamente, em três situações: o sujeito não esperará que alguém decida o que vai lhe ensinar, contanto que a escrita faça parte de seu meio de interação; para se entender a escrita é necessário compreender a forma como ela se desenvolve; e que, ao estudar seu desenvolvimento, percebemos que há modificações das regras do sistema feitas pelo próprio sujeito aprendiz, fazendo-se necessário compreender isso dentro do processo de aprendizagem.

Ao analisar a relação entre linguagem e inteligência, é importante destacarmos as relações entre língua e cognição. O uso do termo língua, na perspectiva de Saussure, assume o caráter geral do aspecto social da linguagem verbal, sendo a língua um sistema abstrato que se concretiza nos atos da fala (SAUSSURE, 1995).

Tomando por base a perspectiva piagetiana, as estruturas cognitivas são construídas a partir de quatro fatores: maturação biológica, exercício e experiência, interações e transmissões sociais e processo de equilibração (PIAGET, 1967). O primeiro desses fatores refere-se ao crescimento orgânico e à maturação do sistema nervoso e endócrino. Para o autor, a maturação tem um papel de destaque durante todo o crescimento mental, mas sobre todo o desenvolvimento.

A maturação consiste, essencialmente, em abrir possibilidades novas e constitui, portanto, condição necessária para o aparecimento de certas condutas, mas sem fornecer as condições suficientes, pois continua a ser indispensável que as possibilidades assim abertas se realizarem e, para isso, que a maturação seja acrescentada de um exercício funcional e de um mínimo de experiência (ibidem, 1967 p.130). 
Tomando por base o argumento de Piaget (1967), concebemos a maturação como um processo importante da criança. Porém, sem que haja a interação com o meio, não há construção de estruturas cognitivas, o que remete ao papel do exercício, da experiência e das interações e transmissões sociais. A partir do interacionismo, o referido autor estudou as condições necessárias para a construção do conhecimento do mundo. Nesse contexto, a linguagem verbal é um componente importante, porém não determinante no processo de construção do conhecimento.

O desenvolvimento das estruturas mentais segue uma construção semelhante aos estudos da lógica. Desse modo, os estudos sobre o desenvolvimento da inteligência ocorrem por meio de dois processos inatos, denominados de organização, isto é, a construção dos processos simples e a adaptação, que nada mais são do que a mudança contínua que ocorrem no indivíduo, a partir da interação com o meio. Para Piaget (1967), as estruturas que caracterizam o pensamento no que concerne à linguagem verbal, têm suas origens na ação e nos mecanismos sensório-motores. Segundo ele, a coordenação entre os meios e os fins nesse período são os primeiros comportamentos genuinamente inteligentes do ser humano. Assim, há um pensamento sensório-motor anterior à linguagem verbal, sendo que a vida social não é a única responsável pelo desenvolvimento dos conceitos, já que existem, no âmbito cognitivo-estrutural, condições necessárias para a aquisição da linguagem verbal (ibidem).

A criança, ao nascer, tem de conhecer o mundo. Para isso, o desenvolvimento predominante nesse momento é o das percepções e movimentos, pois não se pode afirmar, ainda, que a criança pensa. Por volta dos dois anos de idade, a lógica de pensamento da criança apresenta um significativo avanço, derivado a partir da descoberta do símbolo. A realidade passa a ser representada no sentido de que a palavra torna presente o que está ausente. É o momento no qual a criança está centrada em si mesma, tanto no aspecto afetivo quanto no intelectual. Piaget denominou esse momento como egocentrismo. Por volta dos sete anos de idade, o pensamento egocêntrico começa a diminuir, visto que o discurso lógico passa a ser mais objetivo, confrontando com a realidade e com outros discursos. No entanto, mesmo que o pensamento da criança apresente importantes transformações, ele ainda apresenta-se caracterizado pelo egocentrismo, pois a criança ainda não concebe uma realidade da qual não faz parte. Este fato ocorre devido à ausência de esquemas conceituais e da lógica. Seria o mesmo que dizer, por exemplo, a minha casa da minha mãe. O desprendimento da própria 
subjetividade é o sinal de que o egocentrismo intelectual está em processo de superação (PIAGET, 1967).

- Tia...

- O que houve querido?

- Eu não quero emprestar meu Ipad pro "pedrinho" 6

- Não é emprestar porque ele não é seu! É dividir com o coleguinha para que ambos façam as atividades.

- É meu sim!

- Não querido, não é. É da escola. Lembra que todos os dias deixamos ele dentro da caixa mágica?

- É meu sim! Meu pai comprou pra mim.

- o que o seu pai comprou é outro, que fica la na sua casa. Esse é da escola. Ele é um dos filhinhos do Ipad Master. Ele vai ficar triste se um dos seus filhos for embora, e você não quer isso, né?

- É meu. Eu tenho o preto e a minha irmã tem o branco. Esse é preto, então é o meu!. É meu! É meu!

(Diário de Campo, professora 1, aluno G, ano 2013).

Através da linguagem, a criança tem acesso, antes mesmo de aprender a dominar os códigos da fala, a valores, regras e crenças, adquirindo elementos da cultura ao seu redor. À medida que vai se desenvolvendo seu sistema sensorial, como audição e visão, por exemplo, vai alcançando, cada vez mais, um patamar mais elevado tanto do nível linguístico quanto do cognitivo.

Segundo Garton (2007), quanto mais cedo a criança se envolver em relações sociais com seus pares, maior será a possibilidade de interagir com outras pessoas, aumentando o campo de socialização. Quanto maior a interação, maiores os benefícios em curto e em longo prazo, pois as experiências e aprendizagens são o resultado das interações sociais. A partir desse pressuposto, com base no mesmo autor, a compreensão da relação que envolve o desenvolvimento da linguagem e os contextos interativos é fundamental para que se possa perceber como as formas de comunicação estabelecidas com as crianças estão relacionadas com o seu desenvolvimento linguístico, ao passo que as crianças são capazes de exercer influência sobre a forma como as outras pessoas se comunicam com elas. Assim, consideramos de extrema importância um ambiente que possibilite ao aluno ler e escrever objetivando não somente a escola, os ambientes digitais, mas, sobretudo, sua funcionalidade na vida. Um ambiente em que, tanto a linguagem oral quanto a escrita sejam aprendidas no uso e na interação com as pessoas, em que a criança tenha a oportunidade de falar e de escrever

${ }^{6}$ Nome fictício dado ao estudante para manter em sigilo sua identidade. 
sem que a professora esteja preocupada em adivinhar o que ela quer dizer/escrever, mas, acima de tudo, que tente compreender o verdadeiro sentido do que diz e escreve.

Nessa direção, sugere-se que os professores utilizem diferentes abordagens didáticas que estimulem a participação dos alunos, principalmente aqueles sujeitos que apresentam alguma dificuldade de aprendizagem. Para tanto, é fundamental incorporar, em seus recursos didáticos as NTIC, a fim de ampliar as possibilidades de pesquisa, favorecer o diálogo entre os sujeitos, pois esta poderá atuar como uma aliada no processo de ensino e de aprendizagem (PÓVOA, 2000). A utilização da tecnologia paralela à aquisição da linguagem escrita deve ser vista como um processo no qual o domínio desses recursos acontece de forma gradativa. Para tanto, conforme os dados coletados, saber escrever e ler um montante de palavras não é o bastante para letrar uma criança. Com isso, podemos afirmar que, de todos os códigos utilizados pelo homem para expressar suas impressões ao longo da história, para representar coisas ou ideias, o mais importante é, sem dúvida, a língua, um sistema de representação constituído por palavras e por regras que as combinam em unidades portadoras de sentido, comum a todos os membros de um determinado povo ou sociedade (ELY e GLEASON, 1996).

Nesse sentindo, os nativos de uma língua adquirem, de forma natural e gradual, o conhecimento necessário para utilizá-la. Tomemos como base uma criança que, em contato diário com a comunidade falante, começa a emitir palavras soltas, pequenas frases, e, posteriormente, a montar orações mais elaboradas Assim como esse processo ocorre em língua materna, ocorrerá, também, em língua estrangeira, uma vez que quando trabalhamos o uso da escrita, devemos considerar os níveis diferenciados dos nossos alunos quanto ao desenvolvimento da competência tanto linguística quanto comunicativa. Dessa forma, o conhecimento prévio do aluno será acionado e a construção de sentido por eles será favorecida, ao passo que se explore a intertextualidade, os processos coesivos, as estratégias diversificadas de leitura, assim como o uso e as funções do texto escrito. A síntese disso é a compreensão, por parte do aluno, que, ao expressar uma ideia a outro sujeito por meio da fala e da escrita, esta retorna modificada, passando a contribuir para a reformulação e melhor compreensão do que está sendo discutido, pois o novo sentido construído nessa expressão passará a ser traço de união entre os que participam do diálogo, seja ele verbal, seja escrito (SAUSSURE, 1995). 


\section{Compreensões do Processo}

A partir da revolução tecnológica de décadas atrás, levando em conta as diferenças de ordem econômica e social, fator determinante para o acesso às Novas Tecnologias da Informação e Comunicação, a exposição do indivíduo às mais variadas tecnologias ocorre, por vezes, antes mesmo do nascimento. Desde muito pequenas, as crianças têm contato - umas mais, outras menos - com diferentes tipos de mídias, tais como a televisão, o telefone celular, o vídeo game, o computador, o rádio e, mais recentemente, os tablets, de forma a exercerem grande influência na vida social desses sujeitos que, a partir de elementos tanto simbólicos quanto visuais, passam a construir conceitos e percepções do mundo que os rodeia.

Atualmente, ainda se percebe uma dificuldade em romper com arranjos espaciais convencionais que façam parte do ambiente de aprendizagem das crianças, em que elas descubram sua utilização social enquanto brincam, de tal maneira que aprendam tanto sobre si quanto sobre o mundo interagindo com seus pares e com as tecnologias tangíveis. No entanto, a necessidade de controle do que acontece no ambiente educativo ainda está presente nas escolas mais modernas, como a pesquisa, por exemplo, no qual o controle envolve não somente o espaço físico, mas, também, as crianças, as suas relações com o mobiliário e objetos aqui retratados. Isso interfere na imagem organizacional do espaço, na previsibilidade e interferência direta, como o caso do “ipad master”. Assim, a adoção desta vigilância contribui, de forma direta, para as inquietações características da infância.

Independente do modelo de sala de aula, tradicional ou contemporâneo, o ambiente deve ser organizado e preparado para a imaginação, investigação, pesquisa, observação, experimentação e criação do novo, acessível às crianças para uma aprendizagem baseada em autonomia. Desse modo, a construção da linguagem escrita parte de um ambiente rico em estímulos, nos quais os valores sensoriais diversos possibilitam à criança adquirir consciência sobre suas próprias ações, resultando em experiências não fragmentadas através das tecnologias tangíveis que versam pelas táteis, auditivas, visuais, midiáticas e tecnológicas, de forma que o sujeito crie relações com os materiais, assim como com seus pares, e, principalmente com o mundo, utilizando a rede de computadores, podendo, por vezes, confrontar a sua experiência imaginativa com a realidade obtida através do uso da internet, por exemplo. 
Embora faça parte dos objetivos da escola, observamos que a produção de textos é pouco valorizada nos anos iniciais do Ensino Fundamental, em especial no período de alfabetização. Acreditamos que este fato ocorra devido à criança ainda não dominar a ortografia, ou seja, o professor considera esta atividade prematura e, por vezes, a elaboração de textos começa a ganhar força apenas no $3^{\circ}$ ano do Ensino Fundamental. Esta postura vai de encontro ao processo de construção e produção da linguagem escrita, pois, da mesma forma que para desenvolver a leitura é preciso ler, para dominar a escrita - em diferentes tipos de textos, em diferentes plataformas - em relação à forma, é necessário, então, escrever, pois a produção escrita oportuniza ao estudante, muitas vezes, a liberdade de expressão, de errar e criar, levando-o à curiosidade da busca, ou seja, despertando a autonomia.

O professor era tido, praticamente, como a única fonte de transmissão de informações e idas à biblioteca eram obrigatórias para a realização de trabalhos que envolvessem pesquisa. Hoje, cada vez mais a biblioteca física dá lugar à digital, na qual milhares de exemplares são lançados, exclusivamente, nesse formato. Vista sob este aspecto, a prática pedagógica do professor deve desenvolver-se de forma criativa, estimulando a interação do aluno com a leitura e com a escrita para o desenvolvimento da construção textual, sem ter a escrita como forma de punição, mas sim como ato de construção de sentido significativo, seja ela no meio impresso, seja no tangível.

O tablet assume, nesse sentindo, a dimensão tanto do livro quanto do caderno, em que os dedos assumem a função do lápis e da caneta, de forma que as escolas têm que ressignificar as atividades didáticas para o uso pedagógico dessas ferramentas digitais, cujo conhecimento pode ser compartilhado, com cada aluno assumindo a autonomia de sua própria aprendizagem. O aperfeiçoamento desses recursos tecnológicos em ações de manuseio de informações e eficiência da comunicação e construção de linguagem escrita propiciou a seleção natural de grupos que desenvolveram técnicas cada vez mais dinâmicas de construção desta linguagem, de forma que a rapidez, assim como a eficiência da comunicação, passou do telégrafo até chegar ao e-mail em questão de poucos anos, historicamente falando. Com o tempo, a maior amplitude, bem como a velocidade do transporte da informação, determinou quem foram os dominados e os dominantes de uma sociedade, no caso desta pesquisa, a sociedade em rede. O sujeito que domina as novas tecnologias da informação e comunicação é um sujeito que possui imbricado, em si, a cultura de virtualidade 
construída a partir de um sistema de mídia digital onipresente, interligado e altamente diversificado.

\section{REFERÊNCIAS}

ABRÃO, R. K. O espaço físico da sala de aula da Educação Infantil e do primeiro ano e a corporeidade da criança. Fiep Bulletin, v. 84, n. 2, Foz do Iguaçu, 2014.

ABRÃO, R. K.; et al. As diferenças semânticas entre o léxico construído na academia e o produzido na escola pelos professores no ensino de Ciências. Acta Scientae, v. 16, n. 3. Canoas, ULBRA, 2014.

ABRÃO, R. K.; ADAMATTI, D. F. As novas tecnologias da informação e comunicação e a atividade experimental no ensino de ciências. Revista Linhas, Florianópolis, v. 16, n. 31, p. 305 - 324, maio/ago. 2015.

ALMEIDA, F. J. Educação e Informática: os computadores na escola. 5. ed. São Paulo: Cortez, 2012.

AUSTIN, J.L. How to do things with words. Oxford: Oxford University Press, 1976.

BOWMAN, D. A.; et al. 3D User Interfaces: Theory and Practice, Addison-Wesley, 2004.

BRASIL. Secretaria de Educação Fundamental. Parâmetros Curriculares Nacionais: ciências naturais. Secretaria de Educação Fundamental - Brasília: MEC/SEF, 1997.

BUENO, J. F.; LEAL, M. R. O ensino e a aprendizagem de uma língua estrageira. Revista Educação em Movimento, Curitiba, V. 2, n. 6, p-45-56, set-dez. 2003.

CARROLL, J. Foreign languages for children - What research says. The Natl. Elem. School Principal, v. 39, n.6, 12-15, 1960.

CHOMSKY, N. On language: Chomsky's classic works. Language and Responsibility and Reflections on Language. New York: The New Press, 1998.

FERREIRO, E. Alfabetização em processo. São Paulo: Cortez. 1986

GARTON, A. F. Social interaction and the development of language and cognition. Hillsdale: Lawrence Erlbaum, 2007.

GIUSTA, A. da S. Concepções de Aprendizagem e Práticas Pedagógicas. In: Educ.

Rev. Belo Horizonte, v. 1, p. 24 - 31, 1985.

ELY, R, GLEASON B. Socialization across contexts. The handbook of child language. Oxford; 1996.

KATO, M. A concepção da escrita pela criança. Porto Alegre: Artes Médicas, 1998.

KLEIMAN, Â. Os significados do letramento: uma nova perspectiva sobre a prática social da escrita. Campinas: Mercado de Letras, 1995. 
KULIK, J. Effects of using instructional technology in elementary and secondary schools: what controlled evaluation studies say? Arlington: SRI International, 2003. Disponível em:

<http://www.sri.com/policy/csted/reports/sandt/it/Kulik_ITinK12_Main_Report.pdf> Acesso em: 29 dez. 2014.

LANKSHEAR, C.; KNOBEL, M. Digital Literacies: concepts, policies and practices. New York: Peter Lang Publishing, 2008. Acessado em 04 de março de 2012.

LÉVY, P. O Que é o Virtual. São Paulo, Editora 34. 1996.

LÉVY, P. Cibercultura. São Paulo: Editora 34, 1999.

MORATO, E. M. Significação e neurolinguística. Temas em neuropsicologia e neurolingüística, v. 4, p. 26-31, 2000.

PIAGET, J. O raciocínio na criança. Rio de Janeiro/São Paulo: Distribuidora Record, 1967.

PIAGET, J. A formação do símbolo na criança: imitação, jogo e sonho, imagem e representação. Rio de Janeiro: Zahar. 1975.

PIAGET, J. A equilibração das estruturas cognitivas. Rio de Janeiro, RJ: Zahar, 1976.

PÓVOA, M. Anatomia da Internet - investigações estratégicas sobre o universo digital. Rio de Janeiro, Casa da Palavra, 2000.

SAUSSURE, F. de. Curso de Linguística Geral. São Paulo: Cultrix, ed. 20, 1995.

SCHRAMM, W. Notes on case studies of instructional mediaprojects. Working paper, the Academy for Educational Development, Washington, DC, 1971.

WARSCHAUER, M e AMES, M. Can One Laptop per Child Save the World's Poor? Journal of International Affairs, Fall/Winter, v. 64. n.1. 2010.

YIN, R. Estudo de Caso: Planejamento e Métodos. Porto Alegre: Bookman, 2010.

\section{Como referenciar este artigo}

ABRÃO, Kelber Ruhena.; DEL PINO, José Cláudio. Cognição e aprendizagem no espaço da tecnologia. Revista Ibero-Americana de Estudos em Educação, Araraquara, v. 11, n. 4, p. 1776-1798, 2016. Disponível em: <http://dx.doi.org/10.21723/riaee.v11.n4.5934>. E-ISSN: 1982-5587.

Submetido em: março/2014

Aprovação final: julho/2016 